\title{
Desenvolvimento inicial da cana-soca sob lâminas de irrigação de salvamento
}

\section{Initial development of sugarcane under rescue irrigation depths}

Thallita de Sousa Ferreira

Universidade Federal de Viçosa

E-mail: thallita.s.ferreira@gmail.com

OrcID: https://orcid.org/0000-0002-4971-0703

Fernando França da Cunha Universidade Federal de Viçosa

E-mail: fernando.cunha@ufv.br

OrcID: https://orcid.org/0000-0002-1671-1021

Lucas Borges Ferreira

Universidade Federal de Viçosa

E-mail: contato.lucasbf@gmail.com

OrclD: https://orcid.org/0000-0001-6838-3114

Franklin Martins Costa Usina São Martinho-Unidade Boa Vista

E-mail: netucosta@hotmail.com

OrcID: https://orcid.org/0000-0003-1441-4637

Eliziario da Silva Neto

Usina São Martinho-Unidade Boa Vista

E-mail: eliziario.silva@saomartinho.com.br

OrcID: https://orcid.org/0000-0001-7255-3163

Resumo: A cana-de-açúcar é um dos principais produtos agrícolas do Brasil, gerando alimento e energia sustentável para o mundo. No estado de Goiás, o déficit hídrico é um dos fatores limitantes do acúmulo de biomassa, devido à baixa umidade do solo durante praticamente todo o outono e o inverno. Objetivou-se com este trabalho avaliar os efeitos de lâminas de irrigação de salvamento no desenvolvimento inicial da cana-soca de sequeiro, durante os primeiros 30 dias. O experimento foi realizado na Fazenda Isaura, pertencente à Usina São Martinho - Unidade Boa Vista, no município de Quirinópolis, GO. A colheita foi finalizada em 18 de setembro de 2019 e a irrigação ocorreu com Lead Time (dias após colheita) de 7 dias, no dia 25 de setembro de 2019. Utilizou-se o delineamento de blocos casualizados arranjado em faixas. Foram utilizadas cinco lâminas de irrigação (20 mm, $30 \mathrm{~mm}, 40 \mathrm{~mm}, 50 \mathrm{~mm}$ e $60 \mathrm{~mm}$ ), uma testemunha (sem irrigação) e seis repetições. Foram avaliados os parâmetros biofísicos: número de perfilhos por metro linear, altura das plantas e massa fresca dos perfilhos. O número de perfilhos por metro linear, altura das plantas e massa fresca dos perfilhos responderam ao aumento das lâminas de irrigação, em todos os períodos avaliados após o plantio, sendo o modelo de regressão linear o de melhor ajuste. Desde que não supere a capacidade de armazenamento de água no solo, o aumento da lâmina de água proporciona aumento do perfilhamento, altura média das plantas e massa fresca dos perfilhos da cana-soca. A lâmina de irrigação de salvamento de $60 \mathrm{~mm}$ foi a quantidade ótima para potencializar o perfilhamento da cana-soca.

Palavras-chave: Saccharum officinarum; Eficiência de irrigação; Perfilhamento; Carretel enrolador.

Abstract: Sugarcane is one of the main agricultural products in Brazil, generating sustainable food and energy for the world. In the Goiás state, the water deficit is one of the limiting factors for biomass accumulation, given the low soil moisture during almost all autumn and winter. The objective of this study was to evaluate the effect of different rescue irrigation depths on the initial development of rainfed sugarcane, during the first 30 days. The experiment was carried out in the Farm Isaura from São Martinho Plant - Boa Vista Unit, in the municipality of 
Quirinópolis, GO. Harvesting was completed on September 18, 2019, and irrigation occurred 7 days after harvesting (Lead Time), on September 25, 2019. A randomized block design organized in strips was used. Five irrigation depths $(20 \mathrm{~mm}, 30 \mathrm{~mm}, 40 \mathrm{~mm}, 50 \mathrm{~mm}$ and $60 \mathrm{~mm}$ ), one control treatment (without irrigation) and six replications were used. The following biophysical parameters were evaluated: number of tillers per linear meter, plant height, and fresh mass of tillers. The number of tillers per linear meter, plant height, and fresh mass of tillers exhibited significant response due to the increase of irrigation depths in all periods evaluated after planting. The linear regression model showed the best fit. As long as it does not exceed the soil water storage capacity, the increase in irrigation depth provides an increase in tillering, average plant height and fresh mass of tillers. The rescue irrigation depth of $60 \mathrm{~mm}$ was the optimum amount to enhance sugarcane tillering.

Keywords: Saccharum officinarum; Irrigation efficiency; Tillering; Traveler gun.

Data de recebimento: $17 / 01 / 2020$

Data de aprovação: 01/06/2020

DOI: https://doi.org/10.30612/agrarian.v13i50.10909

\section{Introdução}

Historicamente a cana-de-açúcar é um dos principais produtos agrícolas do Brasil. Hoje encontra-se entre as cinco maiores culturas do país. É considerada uma das grandes alternativas para o setor de biocombustíveis devido ao grande potencial na produção de etanol e seus respectivos subprodutos (CONAB, 2019). Entre as grandes culturas, ela se destaca como a planta de maior produção de massa seca e energia por unidade de área em um único corte por ano (SILVA et al., 2014a), podendo chegar a valores de 100 ton ha${ }^{1}$ ano $^{-1}$ (ARAÚJO et al., 2017).

No Brasil, além de atender a demanda interna, a cana-de-açúcar gera alimento e energia sustentável para o mundo. Os principais produtos e subprodutos da cana-de-açúcar são: etanol de primeira e segunda geração ecologicamente correto (hidratado e anidro), açúcar (alimento), bagaço (fonte de energia/bioeletricidade), palha (cobertura vegetal), vinhaça e torta de filtro (biofertilizantes) (JADOSKI et al., 2012; SILVA et al., 2014a; RIBEIRO et al., 2016; COELHO et al., 2018). Na safra 2018/19, o Brasil, maior produtor mundial, produziu aproximadamente 620 milhões de toneladas de cana-de-açúcar. Essa matéria-prima foi utilizada para a produção de 29 milhões de toneladas de açúcar, 33 bilhões de litros de etanol e 21,5 TWh para a rede elétrica nacional (ÚNICA, 2019).

A região Centro-Oeste do Brasil destaca-se no cenário nacional agrícola por apresentar condições favoráveis ao desenvolvimento de grande variedade de culturas graníferas e forrageiras. Outro destaque na última década nessa região têm sido as usinas produtoras de etanol e açúcar (RIBEIRO et al., 2016). No estado de Goiás, segundo maior produtor nacional, há perspectiva de incremento na área em produção na safra 2019/20, estima-se que sejam colhidos 948,3 mil hectares com cana-de-açúcar nesta temporada, 3,4\% maior que os números apresentados em 2018/19 (CONAB, 2019).

Analisando a expansão da cana-de-açúcar, apesar dos grandes volumes de chuva na maior parte do Brasil, existem limitadores de produção. No estado de Goiás, o déficit hídrico é um dos fatores limitantes do acúmulo de biomassa, devido à baixa umidade do solo durante praticamente todo o outono e o inverno. Tal limitação, promove decréscimo nas taxas de fotossíntese e consequente queda de produtividade, sobretudo entre os meses de abril e novembro, os quais compreendem a fase final de crescimento vegetativo, maturação e início do período de perfilhamento da cultura (PEREIRA et al., 2015; ALFACE et al., 2019).

Silva et al. (2014a) observaram que o aumento da disponibilidade hídrica favorece o desenvolvimento da planta, principalmente no estádio de perfilhamento e crescimento vegetativo, o que promove melhor aproveitamento da radiação solar e realização da fotossíntese. O perfilhamento é um dos principais componentes para a formação do potencial de produção da cana-de-açúcar em conjunto com a altura e o diâmetro de colmos (ARAÚJO et al., 2017; COELHO et al., 2018; ARCOVERDE et al., 2019).

Como a irrigação possibilita as variedades expressarem melhor seu potencial genético, muitas usinas estão investindo em uma "irrigação de salvamento" (irrigação no período de estiagem para suprir parcialmente a deficiência hídrica da soqueira). Nestas usinas, irriga-se a cana-soca logo após a colheita, em tempo de espera (Lead Time) em torno de 20 dias, estádio este definido como o qual a cultura mais necessita de água para seu desenvolvimento inicial (brotação e perfilhamento). De acordo com Mauri et al. (2017), o déficit hídrico 
nas primeiras fases pode acarretar o comprometimento do desenvolvimento do sistema radicular e baixo perfilhamento, resultando, portanto, em baixo aproveitamento da água e dos nutrientes disponíveis nos períodos posteriores.

A irrigação de salvamento pode ser realizada por todos os métodos de irrigação. Porém, há uma predominância dos sistemas via aspersão, onde utiliza-se o sistema de carretel enrolador (autopropelido) com canhão hidráulico. Este sistema de irrigação é preferencialmente utilizado nas usinas devido ao baixo custo de implantação e simples operação e manutenção, além da disponibilidade de mão de obra treinada e capacitada para operá-lo. Assim, objetivou-se estudar o efeito de irrigação de salvamento no desenvolvimento inicial da cana-soca.

\section{Material e Métodos}

O experimento foi realizado na Fazenda Isaura, pertencente à Usina São Martinho - Unidade Boa Vista, no município de Quirinópolis, GO. A fazenda está situada na latitude de $18^{\circ} 38^{\prime} 42.0^{\prime \prime} \mathrm{S}$, longitude de $50^{\circ} 16^{\prime}$ 46,2" W e altitude de 541 m (Figura 1).

A

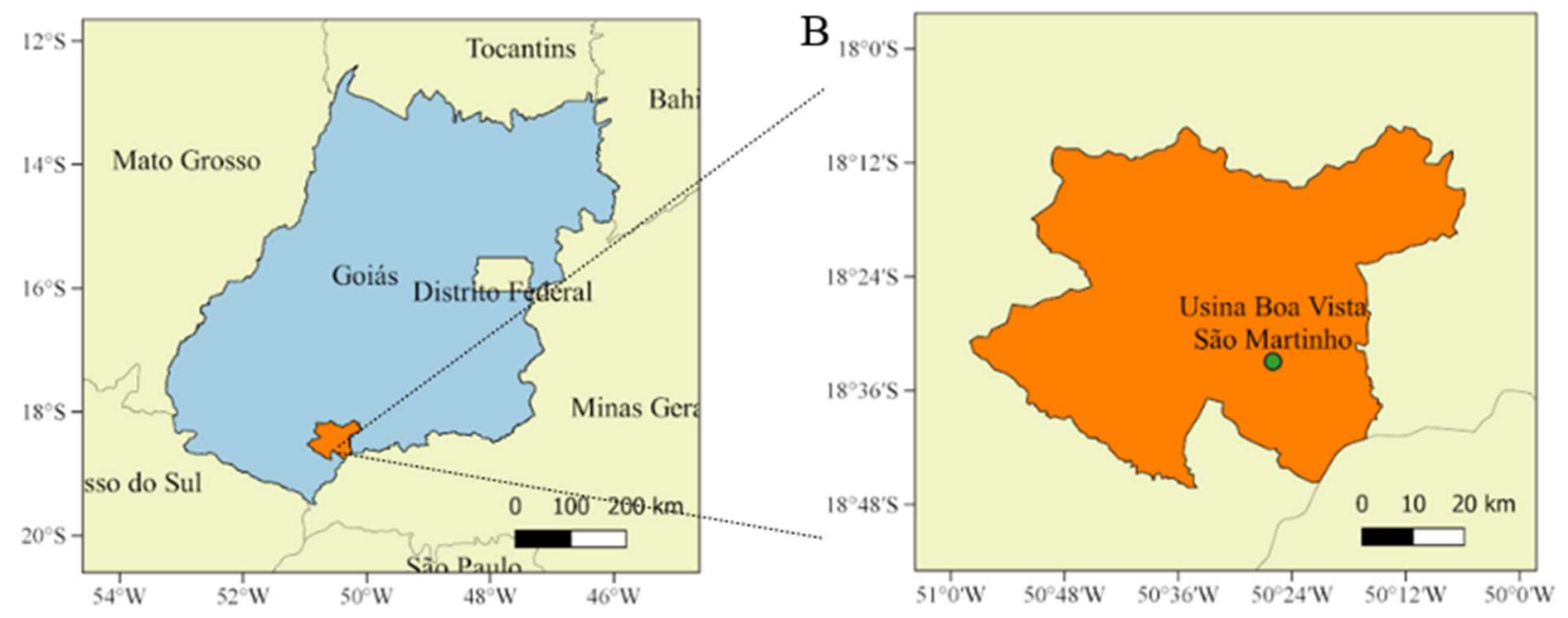

$\mathrm{C}$

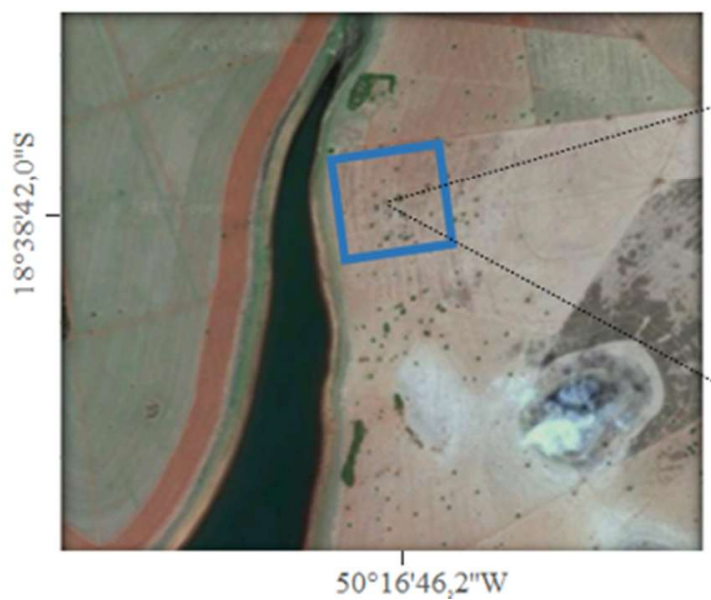

$\mathrm{D}$

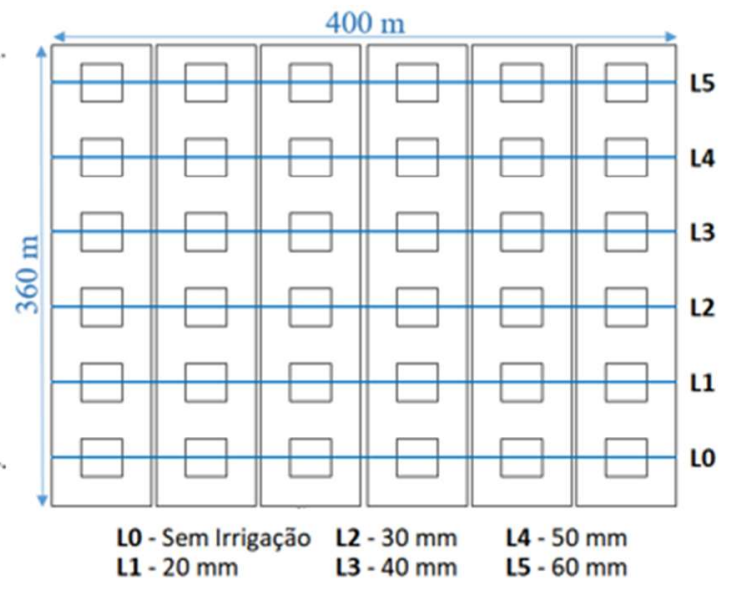

Figura 1. Localização geográfica de Quirinópolis no estado de Goiás (A), Município de Quirinópolis-GO e Usina São Martinho (B), Fazenda Isaura (C) e Arranjo experimental (D).

O clima da região é do tipo Aw, tropical chuvoso, marcadamente sazonal segundo classificação de Köppen (Alvares et al., 2013). De acordo com o Instituto Nacional de Meteorologia (INMET, 2019) a temperatura média anual é de $25,2^{\circ} \mathrm{C}$ com precipitação média de $1240 \mathrm{~mm}$, no último ano.

O solo predominante na área experimental é o LATOSSOLO VERMELHO-AMARELO Distrófico - LVAd segundo o Sistema Brasileiro de Classificação de Solos (SANTOS et al., 2018), de textura média. O ambiente de produção apresenta classificação edafoclimática média. A microrregião é considerada de média aptidão 
agrícola para a cana-de-açúcar por tipos de uso do solo, atualmente utilizadas com pastagens e agricultura, com grande disponibilidade hídrica, associados a relevos suaves ondulados próprios das superfícies regionais de Aplainamento, com declividade menor que $12 \%$ em grandes áreas contínuas, resultado ideal para o plantio da cana (BORGES et al., 2010). As principais características físico-hídricas do solo da área experimental são apresentadas na Tabela 1.

Tabela 1. Características físico-hídricas do solo utilizado: densidade do solo ( $\rho$ ), capacidade de campo -6 kPa (CC) e ponto de murcha permanente $-1.500 \mathrm{kPa}$ (PMP).

\begin{tabular}{cccc}
\hline Camada (cm) & $\mathbf{C C}\left(\mathbf{c m}^{3} \mathbf{~ c m}^{-3}\right)$ & $\mathbf{P M P}\left(\mathbf{c m}^{\mathbf{3}} \mathbf{~ m}^{-3}\right)$ & $\mathbf{P s} \mathbf{~ ( \mathbf { ~ c m } ^ { - 3 } )}$ \\
\hline $0-20$ & 0,301 & 0,143 & 1,41 \\
$20-40$ & 0,296 & 0,141 & 1,48 \\
\hline
\end{tabular}

O conteúdo de água no solo foi medido nos $20 \mathrm{~cm}$ iniciais em toda a área, com o sensor Falker HidroFarm, que mede a impedância do solo em alta frequência (ISAF tecnologia exclusiva do fabricante), emitindo ondas eletromagnéticas e analisando a resposta do solo às mesmas.

A variedade de cana-de-açúcar utilizada no experimento foi a CTC4. Esse material foi plantado em outubro de 2016, sendo que a última colheita foi finalizada em 18 de setembro de 2019. Após isso, em 25 de setembro de 2019, foi realizada a irrigação com Lead Time (dias após a colheita) de 7 dias.

Utilizou-se o delineamento em blocos casualizados arranjado em faixas. Foram utilizadas cinco lâminas de irrigação (20, 30, 40, 50 e $60 \mathrm{~mm}$ ), uma testemunha (0 mm - Condição de sequeiro) e seis repetições (Figura 1). Todas as lâminas foram acrescidas da precipitação pluvial, que foi monitorada, diariamente, por meio de um pluviômetro manual instalado próximo a área experimental. A área total do experimento foi de 14,4 ha, sendo cada faixa com 2,4 ha $(66,66 \mathrm{~m} \times 360 \mathrm{~m})$ constituída de aproximadamente 44 fileiras de cana. As análises foram realizadas nas fileiras centrais de cada faixa.

A cana foi irrigada pela primeira vez com um sistema de autopropelido (carretel enrolador), marca Irrigabrasil TurboMaq modelo 125, equipado com canhão aspersor: modelo Twin 202, bocal cônico, diâmetro $32,5 \mathrm{~mm}$, pressão de serviço de $4 \mathrm{kgf} \mathrm{cm}^{-2}$, vazão $79,5 \mathrm{~m}^{3} \mathrm{~h}^{-1}$ e raio de $57,9 \mathrm{~m}$. O sistema é equipado com uma bomba centrífuga, marca IMBIL, modelo BEW 125, rotação 1750 rpm, multiestágio. O sistema de irrigação foi avaliado quanto à eficiência de aplicação, distribuição e irrigação.

A eficiência de distribuição (Ed) foi obtida por meio do coeficiente de uniformidade de Christiansen (CUC) (Mantovani, 2001), sendo este uma representação estatística da uniformidade, utilizado principalmente em sistemas de irrigação por aspersão e pode ser obtido utilizando-se a Equação 1.

$$
E d(\%)=C U C=100 \times\left(1-\frac{\sum_{i=1}^{n}|X i-\bar{X}|}{n \bar{X}}\right)
$$

Em que: $\mathrm{n}$ - número de coletores ou pluviômetros; Xi - lâmina de água aplicada no i-ésimo ponto sobre a superfície do solo ( $\mathrm{mm}) ; \bar{X}$ - lâmina média aplicada $(\mathrm{mm})$.

Para a avaliação, foram dispostos 46 coletores conforme o esquema abaixo (Figura 2), sendo o primeiro espaçado de $0,5 \mathrm{~m}$ devido a passagem do carrinho.

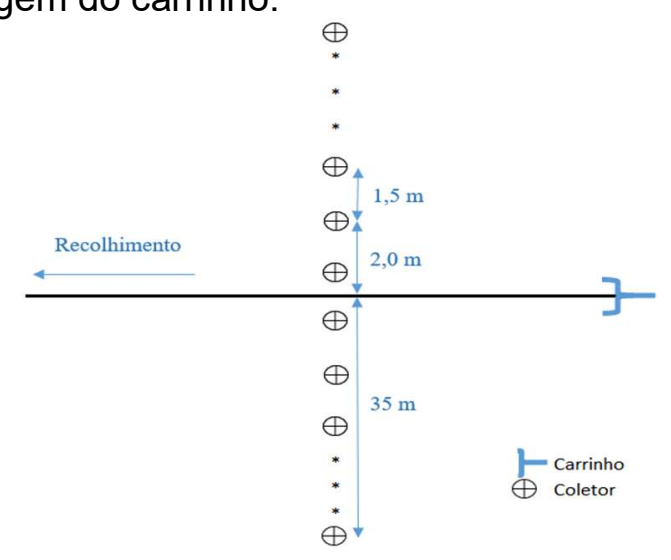

Figura 2. Disposição dos coletores. 
A eficiência de aplicação (Ea) foi obtida comparando-se a lâmina aplicada com a lâmina média coletada (média da lâmina de todos os coletores) (Equação 2).

$$
E a(\%)=100 \times\left|\frac{\mathrm{Lc}}{L a}\right| \quad \text { Eq.(2) }
$$

Em que: La - lâmina de água aplicada (mm); Lc - lâmina média coletada (mm).

As perdas por evaporação e arraste (PEA) foram obtidas por meio da Ea (Equação 3).

$$
P E A(\%)=100 \times(1-E a) \quad \text { Eq.(3) }
$$

E a eficiência de irrigação (Ei) foi obtida pelo produto da Ed pela Ea (Equação 4).

$$
E i(\%)=100 \times E d \times E a \quad \text { Eq.(4) }
$$

A velocidade do vento, a $2 \mathrm{~m}$ de altura, foi verificada com um anemômetro (Kestrel 3000) em três momentos durante a aplicação: início, meio e fim, sendo realizada dez medidas em cada um dos momentos. Ao término da irrigação, obteve-se a média da velocidade do vento.

Durante o experimento foram monitoradas as variáveis meteorológicas (radiação solar, velocidade do vento, temperaturas máxima e mínima e, umidade relativa máxima e mínima do ar) por meio de uma estação agrometeorológica automática da Usina São Martinho, para determinar a evapotranspiração de referência por Penman-Monteith (ALLEN et al., 1998).

Para a avaliação do perfilhamento, foram selecionados dois metros lineares de duas fileiras centrais da faixa (unidade experimental). O número de perfilhos (unidade) foi contado manualmente com 15 e 30 dias após a irrigação de salvamento, assim como as demais características avaliadas.

No centro de cada parcela, foram medidas a altura $(\mathrm{cm})$ de cinco plantas por parcela. A altura da planta foi aquela correspondente à distância entre a superfície do solo e o ponto mais alto da folha mais velha da planta.

Em um metro linear de cada parcela foi avaliada a massa fresca dos perfilhos $(\mathrm{g})$ conforme Segato e Carvalho (2018). Os perfilhos foram cortados rente ao solo e na sequência pesados em uma balança digital portátil (capacidade de $10 \mathrm{~g}$ a $50 \mathrm{~kg}$ ).

Os dados foram submetidos à análise de regressão. As avaliações realizadas com 15 e 30 dias após a irrigação foram analisadas de forma independente. Foram testados modelos lineares e quadráticos. A seleção dos modelos foi feita com base na significância dos coeficientes de regressão, utilizando-se o teste t a $5 \%$ de probabilidade, no coeficiente de determinação $\left(R^{2}\right)$ e no fenômeno biológico. Para execução das análises estatísticas foi utilizado o software "R" (R DEVELOPMENT CORE TEAM, 2017).

\section{Resultados e Discussão}

Os resultados das avaliações do sistema de irrigação por carretel enrolador estão apresentados na Tabela 2. Na maioria dos tratamentos, verificou-se que a eficiência de distribuição (Ed) do sistema de irrigação, dada pelo coeficiente de uniformidade de Christiansen (CUC), foi "Boa" conforme a classificação de Mantovani (2001). No tratamento de lâmina de irrigação de 30 mm, a Ed apresentou classificação "Ruim" de acordo com a classificação de Mantovani (2001). Possivelmente, esse baixo desempenho foi devido às rajadas de vento ocorridas no momento em que o equipamento se deslocava acima dos pluviômetros. Esse fato pode ser confirmado pela eficiência de aplicação (Ea), em que o tratamento de lâmina de $30 \mathrm{~mm}$ apresentou o menor valor de Ea e maior valor de perdas de água por evaporação e arraste (PEA). A velocidade do vento, além de reduzir a eficiência de distribuição, também reduz a eficiência de aplicação devido potencializar a deriva (CUNHA et al., 2012; MORAES et al., 2017). 
Tabela 2. Eficiência de distribuição (Ed), coeficiente de uniformidade de Christiansen (CUC), eficiência de aplicação (Ea), perdas por evaporação e arraste (PEA), velocidade média do vento e eficiência de irrigação (Ei) do sistema carretel enrolador no momento da aplicação de cada lâmina de irrigação.

\begin{tabular}{cccccc}
\hline $\begin{array}{c}\text { Lâminas de } \\
\text { irrigação (mm) }\end{array}$ & $\begin{array}{c}\text { Ed (\%) } \\
\text { CUC (\%) }\end{array}$ & Ea (\%) & PEA (\%) & $\begin{array}{c}\text { Velocidade do } \\
\left.\text { vento (km } \mathbf{~ h}^{-1}\right)\end{array}$ & Ei (\%) \\
\hline 0 & - & - & - & - & - \\
20 & 83,1 & 91,4 & 8,6 & 3,85 & 76,0 \\
30 & 69,5 & 91,0 & 9,0 & 6,51 & 63,2 \\
40 & 86,7 & 96,9 & 3,1 & 3,24 & 84,0 \\
50 & 82,2 & 99,1 & 0,9 & 6,78 & 81,5 \\
60 & 88,9 & 99,6 & 0,5 & 6,41 & 88,5 \\
\hline
\end{tabular}

Os valores de PEA do sistema de irrigação por carretel enrolador ficaram abaixo de $10 \%$ para todas as lâminas, proporcionando altos valores de Ea. Esses altos valores de Ea aconteceram devido as aplicações das irrigações acontecerem no início do dia, momentos com baixas temperaturas do ar e baixo déficit de pressão de vapor, reduzindo as perdas por evaporação. É oportuno ressaltar que os sistemas de carretel enrolador são conhecidos por apresentarem baixos valores de Ea (MORAES et al., 2017). Já os valores de eficiência de irrigação (Ei), que é a multiplicação da Ed pela Ea, variaram nos diferentes tratamentos entre 63 e $88 \%$ e apresentou média de $78,6 \%$. Esse valor médio de Ei indica que a lâmina de irrigação (lâmina bruta) deverá ser 27,2\% maior que a lâmina de reposição hídrica (lâmina líquida), ou seja, para cada $10 \mathrm{~mm}$ necessário para reposição hídrica, uma lâmina de irrigação de 12,72 mm deverá ser aplicada. Esses 2,72 mm excedentes a serem aplicados seria para compensar as perdas por evaporação e arraste e a desuniformidade de distribuição da água pelo sistema de irrigação.

A variação da evapotranspiração de referência (ETo) e da precipitação pluvial durante o experimento estão apresentadas na Figura 3. A ETo média, no período experimental, foi de $5,66 \mathrm{~mm} \mathrm{~d}^{-1}$. Considerando o coeficiente de cultivo (Kc) para os estágios iniciais igual a 0,56 (Silva et al., 2014b), a evapotranspiração média da cultura (ETc) da cana-de-açúcar foi de $3,17 \mathrm{~mm} \mathrm{~d}^{-1}$. A ETc acumulada para o mesmo período foi de 139,4 $\mathrm{mm}$. Durante o período experimental, aconteceram três eventos de precipitação pluvial, proporcionando um acumulado de $83,0 \mathrm{~mm}$. Assim, entende-se que, mesmo considerando a ocorrência das precipitações pluviais, a cultura da cana-de-açúcar sofreu déficit hídrico. Esse fato pode ser confirmado pela variação da lâmina atual de água (LAA) no solo ao longo do período experimental, para os diferentes tratamentos (Figura 4).

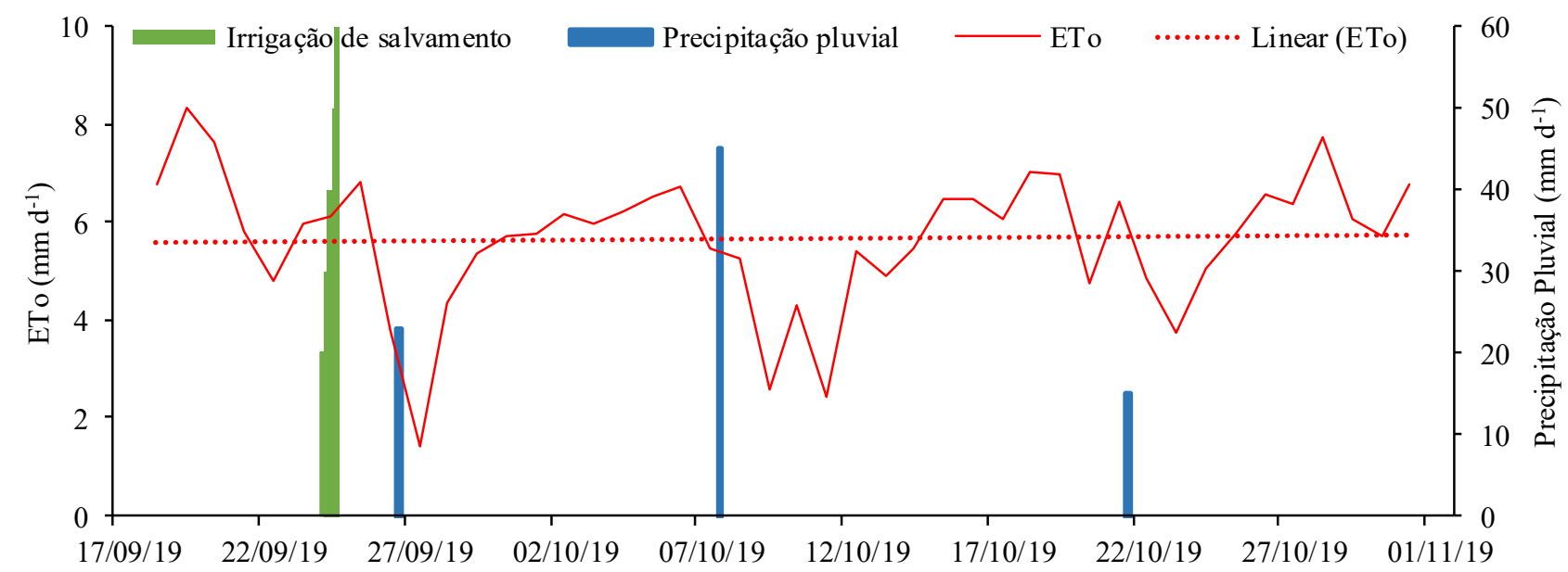

Figura 3. Lâminas de irrigação de salvamento, precipitação pluvial e evapotranspiração de referência (ETo) durante o período experimental.

Verifica-se também na Figura 4 que nenhuma lâmina de irrigação de salvamento foi suficiente para elevar a umidade do solo até a capacidade de campo (CC). Após isso, a umidade do solo foi reduzindo devido ao processo de evapotranspiração da cana-soca, sendo que o tratamento que não recebeu irrigação aproximou da umidade equivalente ao ponto de murcha permanente (PM). Verifica-se também que até o dia 7 de outubro de 2019 os solos dos tratamentos apresentaram diferentes LAA. Nessa data, ocorreu uma chuva de $45 \mathrm{~mm}$ e 
os tratamentos que receberam lâminas de irrigação de salvamento superiores a $40 \mathrm{~mm}$ tiveram elevação da umidade dos seus solos até a CC. Assim, a partir dessa data, as LAA's dos solos dos tratamentos que receberam lâminas superiores a $40 \mathrm{~mm}$ foram reduzidas, mas não diferiram entre si.

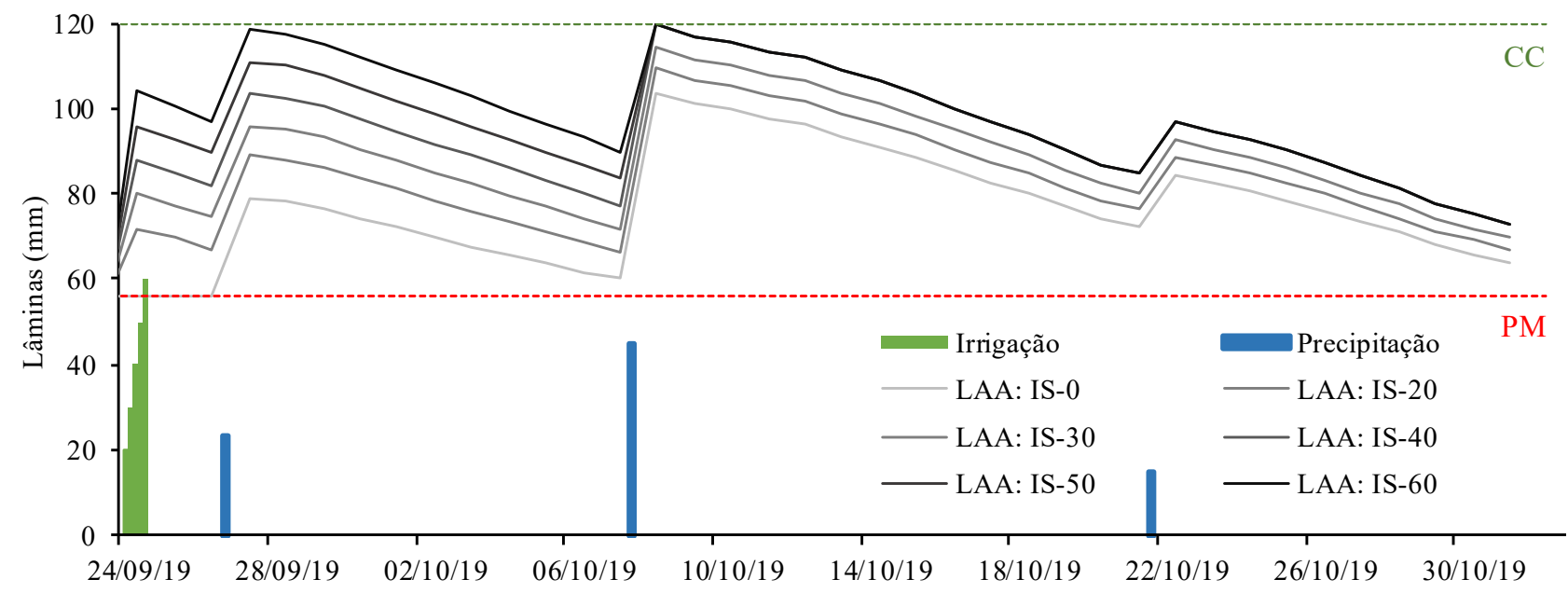

Figura 4. Irrigação de salvamento, precipitação pluvial e lâminas atuais de água (LAA) no solo nos diferentes tratamentos com lâminas de irrigação de salvamento (IS) durante o período experimental.

O perfilhamento apresentou comportamento crescente em função do aumento das lâminas de água total em todos os períodos avaliados após a colheita, como pode ser observado na Figura 5. Entende-se por lâmina total, o somatório da água recebida via irrigação e precipitação pluvial. Até $015^{\circ}$ dia de avaliação havia precipitado um acumulado de $68 \mathrm{~mm}$ e até o $30^{\circ}$ dia choveu mais $15 \mathrm{~mm}$, acumulando um total de $83 \mathrm{~mm}$. Esses acumulados foram adicionados a irrigação de salvamento para ajustar o modelo de regressão. Verificouse para as duas datas de avaliação que o modelo linear positivo foi aquele que melhor se ajustou aos dados. Dessa forma, pode-se sugerir que o aumento da lâmina de água proporciona aumento linear no perfilhamento da cana-soca. Silva et al. (2014a) observaram que o aumento da disponibilidade hídrica favorece o desenvolvimento da planta, sobremaneira no estádio de perfilhamento e crescimento vegetativo, o que promove melhor aproveitamento da radiação solar e realização da fotossíntese. Dessa forma, acredita-se que a irrigação de salvamento possa potencializar a produtividade dos canaviais.

Na Figura 5, observa-se que houve resposta positiva em termos de perfilhamento para os tratamentos que receberam irrigação de salvamento em relação à testemunha $(0 \mathrm{~mm})$, na qual recebeu água apenas por meio de precipitação pluvial. Possivelmente, a cana-soca no tratamento sem irrigação sofreu déficit hídrico diminuindo seu desempenho perante os outros tratamentos. Quando as plantas estão sofrendo déficit hídrico, as células-guarda, localizadas nos estômatos, apresentam-se com menor turgidez e a abertura estomática é reduzida, resultando em menores taxas de absorção de $\mathrm{CO}_{2}$. A consequência disso é a redução da fotossíntese e redução de novas folhas. Desta forma, os processos fisiológicos são comprometidos acarretando em perdas na produtividade e qualidade do produto. O estresse hídrico também causa efeito de desidratação das células o que pode acarretar concentração de íons que tornarão tóxicos para o ambiente celular (TAIZ \& ZEIGER, 2013; CUNHA et al., 2019).

Coelho et al. (2018) encontraram que o pico de perfilhamento da cana, em dois anos de avaliação, foi antecipado em 30 dias quando manejada sob irrigação. Os autores relataram que o incremento no perfilhamento sob condições irrigadas para cana-soca foi mais pronunciado, uma vez que as condições climáticas após a colheita não favoreceram o crescimento da cana-de-açúcar manejada sob sequeiro, principalmente pela baixa precipitação da região no mês de outubro, que foi de apenas $57 \mathrm{~mm}$ (COELHO et al., 2018). Além disso, outro fator que influência o alto perfilhamento em apenas 30 dias deve-se ao sistema radicular que já estava estabelecido, por se tratar de cana-soca (ARCOVERDE et al., 2019). 
A

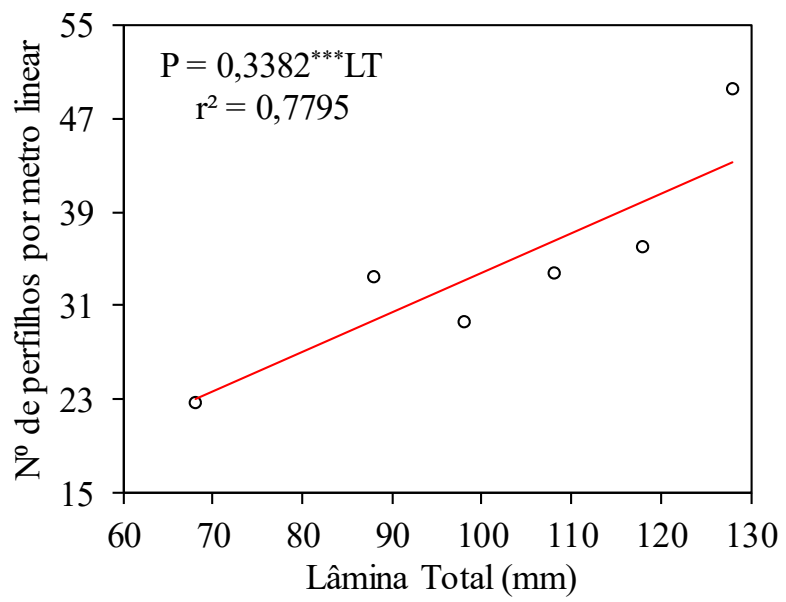

B

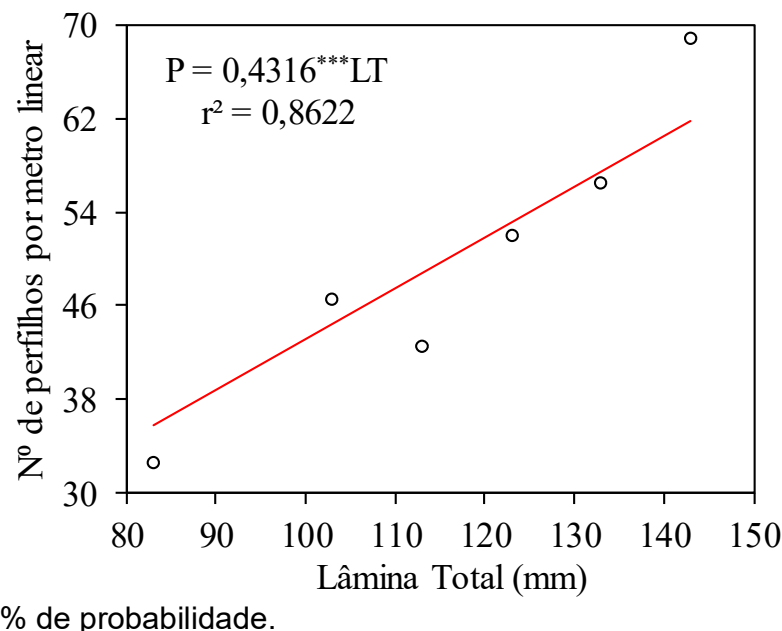

Figura 5. Perfilhamento da cana-soca em função de lâminas de água total (irrigação por salvamento + precipitação pluvial) aos (A) 15 e (B) 30 dias após irrigação.

Utilizando-se a equação de regressão da Figura 5B, obtêm-se um comportamento ascendente da média do número de perfilhos da cana-soca irrigada comparando-se com a de sequeiro, chegando a até $103,5 \%$ de incremento para lâmina de $60 \mathrm{~mm}$. Porém, altas lâminas em solos arenosos podem ser perdidas por percolação, por isso recomenda-se um estudo da capacidade total de armazenamento de água no solo antes da realização da irrigação.

Verifica-se também na Figura 5 que o tratamento com lâmina de salvamento de $30 \mathrm{~mm}$ apresentou um comportamento diferente das demais. Percebe-se que esse tratamento apresentou as menores médias dentre os tratamentos com irrigação, muito provavelmente devido à baixa eficiência de irrigação verificada nesse tratamento (Tabela 2). Então percebe-se que a baixa eficiência de irrigação proporciona grandes prejuízos econômicos, uma vez que reduz o potencial produtivo e aumenta o gasto de energia elétrica.

Observa-se na Figura 6 que o aumento da lâmina total de água proporcionou aumento na massa fresca dos perfilhos da cana-soca. Assim, quanto maior a lâmina, maior o potencial produtivo, uma vez que a irrigação de salvamento no período de estiagem supriu parcialmente a deficiência hídrica da soqueira, favorecendo seu desenvolvimento inicial. Perfilhos formados mais cedo contribuem para a produção de colmos mais grossos e mais pesados, enquanto os formados mais tardiamente morrem ou permanecem curtos ou imaturos (MANHÃES et al., 2015).

A

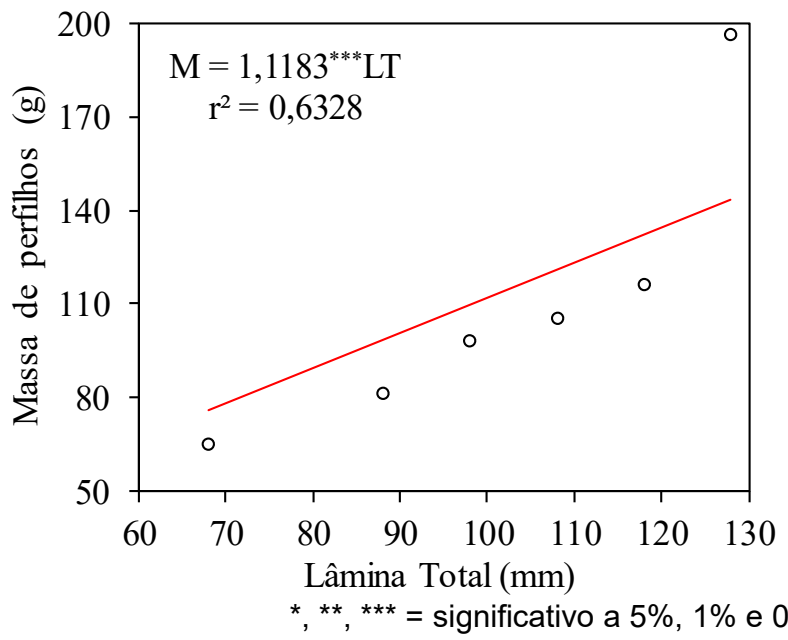

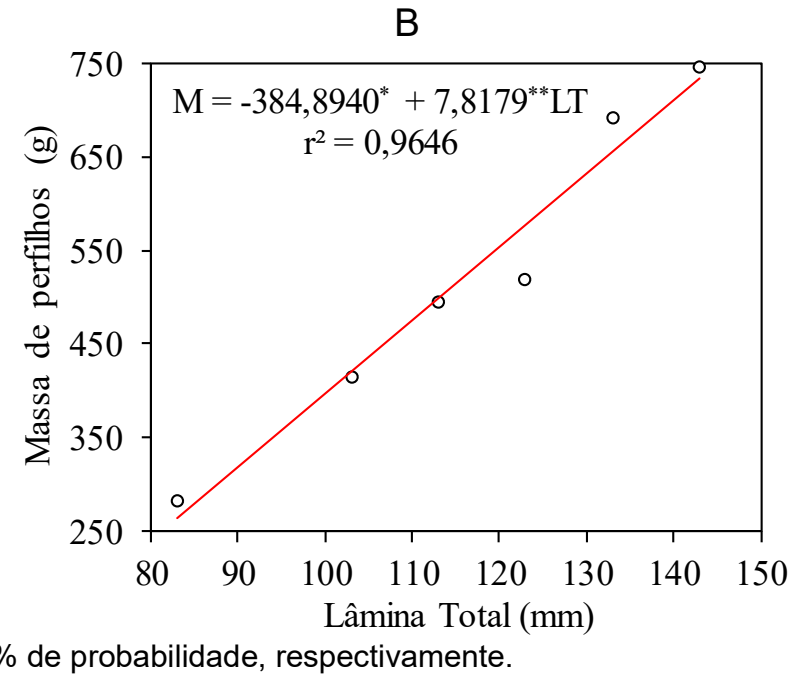

Figura 6. Massa fresca dos perfilhos em função de lâminas de água total (irrigação por salvamento + precipitação pluvial) aos (A) 15 e (B) 30 dias após irrigação. 
As reduções da massa fresca dos perfilhos em função da redução da lâmina total de água (irrigação de salvamento + chuva), quando é comparado os extremos utilizando-se a equação de regressão, são de 67 e $62 \%$ nas avaliações realizadas após 15 e 30 dias da aplicação da irrigação de salvamento, respectivamente. Resultados similares foram observados por Jadoski et al. (2012), em seu estudo sobre o desenvolvimento morfofisiológico de raízes e perfilhos da cana-de-açúcar. Neste trabalho os autores relatam que o potencial mátrico próximo de zero (equivalente à condição de capacidade de campo) proporcionou melhores taxas de desenvolvimento inicial. Já o potencial de $15 \mathrm{~atm}$, equivalente ao ponto de murcha permanente, resultou em uma redução na porcentagem de perfilhamento de 65,6\%; além de verificar redução da altura, massa fresca e seca de perfilhos e comprimento das raízes da cana-de-açúcar. De acordo com Mauri et al. (2017), o déficit hídrico nas primeiras fases pode acarretar o comprometimento do desenvolvimento do sistema radicular e baixo perfilhamento, resultando, portanto, em baixo aproveitamento da água e dos nutrientes disponíveis nos períodos posteriores.

Verifica-se na Figura 7 que a altura das plantas da cana-soca apresentou crescimento linear em função da lâmina total de água recebida. Os acréscimos na altura de planta, em função do aumento da lâmina total de água (irrigação de salvamento + chuva), foram de 18 e 15\% para as avaliações realizadas após 15 e 30 dias da aplicação da irrigação de salvamento, respectivamente. Coelho et al. (2020) aplicaram diferentes manejos hídricos na produção de cana-de-açúcar em experimento realizado em Jaboticabal, SP. Os autores verificaram, para diversas variedades de cana-de-açúcar, maiores alturas para os tratamentos com irrigação suplementar, seguida do tratamento com irrigação com déficit e, posteriormente, pelo tratamento sem irrigação. Da mesma forma, Silva et al. (2008) avaliando várias variedades de cana-de-açúcar sob condições de déficit hídrico, concluíram que o número de perfilhos e altura das plantas são influenciadas negativamente por condições de déficit hídrico durante a fase de crescimento inicial.

A

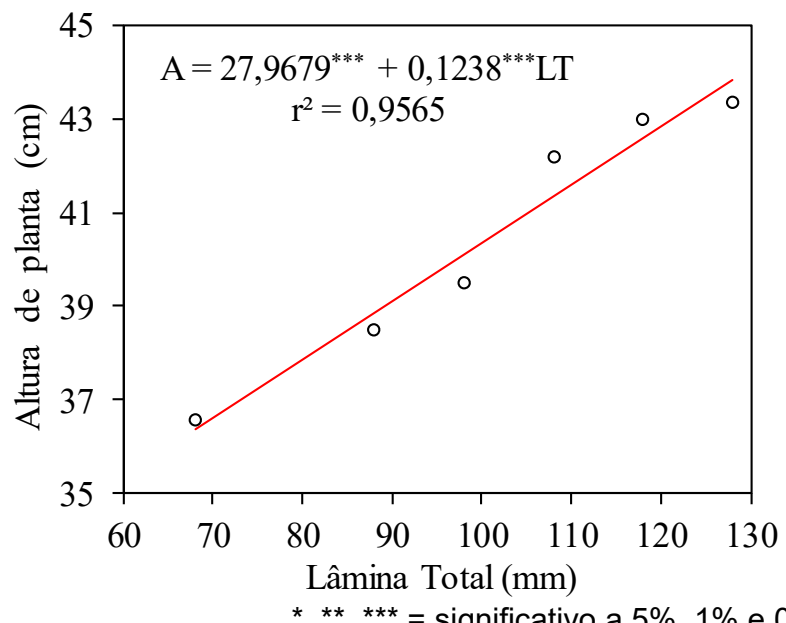

B

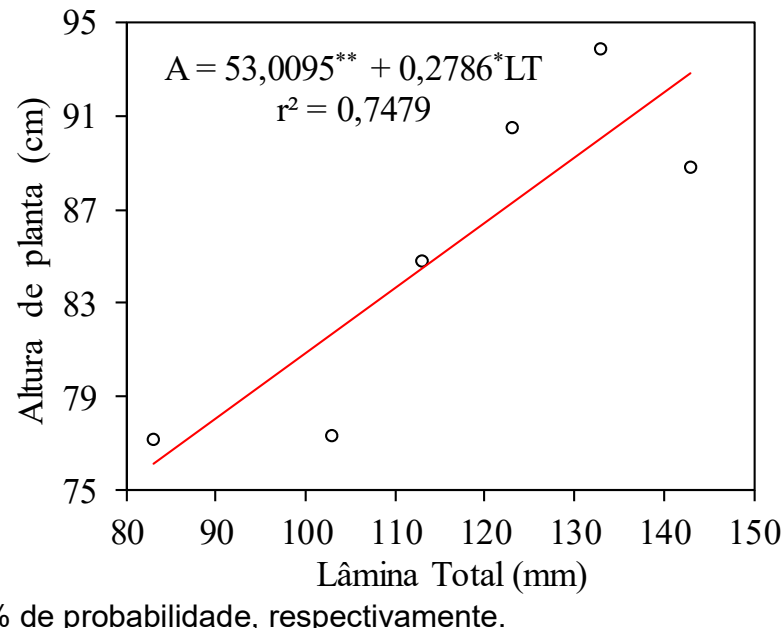

Figura 7. Altura das plantas em função de lâminas de água total (irrigação por salvamento + precipitação pluvial) aos (A) 15 e (B) 30 dias após irrigação.

É oportuno ressaltar que na presente pesquisa não houve aplicação de lâminas de irrigação, ou chuvas, que superassem a necessidade hídrica da cana-soca, assim, a capacidade máxima de armazenamento de água no solo não foi atingida. Dessa forma, não existiu excesso de água que pudesse causar hipóxia e/ou lixiviação de nutrientes no solo e, assim, justificando o motivo de todas as características avaliadas apresentarem respostas lineares. Silva et al. (2019) aplicaram lâmina de irrigação que superaram em 10 e $50 \%$ a necessidade hídrica da cana-de-açúcar e verificaram redução das características agronômicas avaliadas, em experimento realizado em Teresina, $\mathrm{PI}$.

A resposta em produtividade para cana-de-açúcar irrigada depende de um conjunto de fatores, além da quantidade de água fornecida. Logo, além do número de perfilhos, massa fresca dos perfilhos e altura das plantas, indica-se também um estudo da variedade, número de corte, tipo de solo, fornecimento de fertilizantes e do clima da região. 


\section{Conclusões}

Desde que não supere a capacidade máxima de armazenamento de água no solo, o aumento da lâmina de água proporciona aumento do perfilhamento, altura média das plantas e massa fresca dos perfilhos da canasoca.

A lâmina de irrigação de salvamento de $60 \mathrm{~mm}$ foi a quantidade ótima para potencializar o perfilhamento da cana-soca.

\section{Referências}

ALFACE, A.B.; PEREIRA, S.B.; FILGUEIRAS, R.; CUNHA, F.F. Sugarcane spatial-temporal monitoring and crop coefficient estimation through NDVI. Revista Brasileira de Engenharia Agrícola e Ambiental, Campina Grande, v.23, n.5, p.330-335, 2019.

ALLEN, R.G.; PEREIRA, L.S.; RAES, D.; SMITH, M. Crop evapotranspiration: Guidelines for computing crop water requirements. Irrigation and Drainage Paper, 56. Rome: FAO, p.300, 1998.

ALVARES, C.A.; STAPE, J.L.; SENTELHAS, P.C.; MORAES, G.; LEONARDO, J.; SPAROVEK, G. Köppen's climate classification map for Brazil. Meteorologische Zeitschrift, Berlin, v.22, n.6, p.711-728, 2013.

ARAÚJO, R.M.; OLIVEIRA, R.A.; CUADRA, S.V.; ALMEIDA, I.R.; WEBER, H. Condições agrometeorológicas para perfilhamento máximo da cultura de cana-de-açúcar em dois ambientes distintos de produção. Agrometeoros, Passo Fundo, v.25, n.1, p.257-264, 2017.

ARCOVERDE, S.N.S.; SOUZA, C.M.A.; ORLANDO, R.C.; SILVA, M.M.; NASCIMENTO, J.M. Crescimento inicial de cultivares de cana-de-açúcar em plantio de inverno sob preparos conservacionistas do solo. Engenharia na Agricultura, Viçosa, v.27, n.2, p.142-156, 2019.

BORGES, V.M.S.; SILVA, A.A.; CASTRO, S.S. Caracterização edafoclimática da microrregião de QuirinópolisGO para o cultivo da cana-de-açúcar. In: Simpósio Nacional de Geomorfologia, 8, 2010 Recife. Anais... Recife: UFPE, 2010.

COELHO, A.P.; DALRI, A.B.; FARIA, R.T.; LANDELL, P.A.; PALARETTI, L.F. Perfilhamento da cana-de-açúcar cultivada com e sem irrigação suplementar e plantada por mudas pré-brotadas: Um novo conceito. Acta Iguazu, Cascavel, v.7, n.4, p.71-84, 2018.

COELHO, A.P.; DALRI, A.B.; FISCHER FILHO, J.A.; FARIA, R.T.; SILVA, L.S.; GOMES, R.P. Calibration and evaluation of the DSSAT/Canegro model for sugarcane cultivars under irrigation managements. Revista Brasileira de Engenharia Agrícola e Ambiental, Campina Grande, v.24, n.1, p.52-58, 2020.

CONAB - Companhia Nacional de Abastecimento. Safra brasileira de cana-de-açúcar, 2019. Disponível em: <https://www.conab.gov.br/info-agro/safras/cana>. Acesso em: 16/01/2020.

CUNHA, F.F.; VIEIRA, G.H.S.; SOUZA, J.A.R.; BATISTA, R.O.; VICENTE, M.R. Uniformidade de distribuição de água em pivô central. Engenharia na Agricultura, Viçosa, v.20, n.2, p.151-162, 2012.

CUNHA, F.F.; SOUZA, I.P.; CAMPOS, W.O.; ANDRADE JUNIOR, V.C.; MAGALHAES, T.A. Agronomic performance of radish genotypes under different irrigation depths. Engenharia Agrícola, Jaboticabal, v.39, n.2, p.182-190, 2019.

INMET - Instituto Nacional de Meteorologia. Estação meteorológica de observação de superfície automática, 2019. Disponível em: <http://www.inmet.gov.br>. Acesso em: 10/12/2019.

JADOSKI, C.J.; TOPPA, E.V.B.; RODRIGUES, J.D. Desenvolvimento morfofisiológico de raízes e brotos da cana-de-açúcar (Saccharum officinarum L.). Scientia Agraria Paranaensis, Cascavel, v.11, n.2, p.22-32, 2012.

MANHÃES, C.M.C.; GARCIA, R.F.; FRANCELINO, F.M.A.; FRANCELINO, H.; COELHO, F.C. Fatores que afetam a brotação e o perfilhamento da cana-de-açúcar. Vértices, São Paulo, v.17, n.1, p.163-181, 2015.

MANTOVANI, E.C. Avalia: Programa de avaliação da irrigação por aspersão e localizada. Viçosa: UFV, 2001. 
MAURI, R.; COELHO, R.D.; FRAGA JUNIOR, E.F.; BARBOSA, F.S.; LEAL, D.P.V. Water relations at the initial sugarcane growth phase under variable water deficit. Engenharia Agrícola, Jaboticabal, v.37, n.2, p.268-276, 2017.

MORAES, D.D.V.; FORATTO, L.C; GUALBERTO, R. Sistema de irrigação por aspersão via autopropelido: Revisão de literatura. Unimar Ciências, Marília, v.26, n.1-2, p.163-169, 2017.

PEREIRA, R.M.; ALVES JÚNIOR, J.; CASAROLI, D.; SALES, D.L.; RODRIGUEZ, W.D.M.; SOUZA, J.M.F. Viabilidade econômica da irrigação de cana-de-açúcar no cerrado brasileiro. Irriga, Botucatu, v.1, n.2, p.149157, 2015

R DEVELOPMENT CORE TEAM. R: A Language and environment for statistical computing. Vienna, $R$ Foundation for Statistical Computing. [S.I: s.n.], 2017.

RIBEIRO, D.O.; CARBALLAL, M.R.; SILVA, A.J.; SANTOS, T.E.B.; FERREIRA, L.L.; CUNHA, F.F. Produtividade de cana-de-açúcar e atributos de solo em função da aplicação de cama de peru. Revista de Ciências Agrárias, Belém, v.59, n.3, p.259-264, 2016.

SANTOS, H.G.; JACOMINE, P.K.T.; ANJOS, L.H.C.; OLIVEIRA, V.Á.; LUMBRERAS, J.F.; COELHO, M.R.; ALMEIDA, J.A.; ARAÚJO FILHO, J.C.; OLIVEIRA, J.B.; CUNHA, T.J.F. Sistema Brasileiro de Classificação de Solos (SiBCS). 5.ed. Brasília: Embrapa Solos, 2018. 356p.

SEGATO, S.V.; CARVALHO, M.R.B. Acompanhamento mensal do crescimento da parte aérea em canavial de segundo corte. Nucleus, Ituverava, v.15, n.1, p.161-180, 2018.

SILVA, M.A.; SOARES, R.A.B; LANDELL, M.G.A.; CAMPANA, M.P. Agronomic performance of sugarcane families in response to water stress. Bragantia, Campinas, v.67 n.3, p.655-661, 2008.

SILVA, M.A.; ARANTES, M.T.; RHEIN, A.F.L.; GAVA, G.J.C.; KOLLN, O.T. Potencial produtivo da cana-deaçúcar sob irrigação por gotejamento em função de variedades e ciclos. Revista Brasileira de Engenharia Agrícola e Ambiental, Campina Grande, v.18, n.3, p.241-249, 2014a.

SILVA, V.P.R.; BORGES, C.J.R.; ALBUQUERQUE, W.G. Necessidades hídricas da cana-de-açúcar cultivada em clima tropical. Semina: Ciências Agrárias, Londrina, v.35, n.2, p.625-632, 2014b.

SILVA, E.M.P.; ANDRADE JÚNIOR, A.S.; BASTOS, E.A.; RIBEIRO, V.Q. Produtividade de colmos e eficiência do uso da água em cana-de-açúcar irrigada por gotejamento subsuperficial. Irriga, Botucatu, v.24, n.1, p.162176, 2019.

TAIZ, L.; ZEIGER, E. Fisiologia vegetal. 5.ed. Porto Alegre: Artmed, 2013. 918p.

ÚNICA - União da Agroindústria Canavieira do Estado de São Paulo. A união da indústria de cana-de-açúcar, 2019. Disponível em: <http://www.unica.com.br>. Acesso em: 17/01/2020. 